\title{
The Distribution of Phosphodiesterase 2a in the Rat Brain
}

\author{
D. T. Stephenson ${ }^{a}, \dagger$, T. M. Coskran ${ }^{b}$, M. P. Kelly ${ }^{a} \ddagger$, R. J. Kleiman ${ }^{a}$, , D. Morton ${ }^{c}$, S. M. \\ O'neilla ${ }^{\mathrm{a}}$ C. J. Schmidta ${ }^{\mathrm{a}}$, R. J. Weinberg ${ }^{\mathrm{d}}$, and F. S. Mennitia, ${ }^{*}$
}

D. T. Stephenson: DStephenson@c-path.org; M. P. Kelly: Michy.Kelly@uscmed.sc.edu; R. J. Kleiman: kleimanrj@gmail.com; F. S. Menniti: mennitifs@gmail.com

aNeuroscience Biology, Pfizer Global Research \& Development, Eastern Point Road, Groton, CT 06340, USA

' Investigative Pathology, Pfizer Global Research \& Development, Eastern Point Road, Groton, CT 06340, USA

'Toxologic Pathology, Pfizer Global Research \& Development, Eastern Point Road, Groton, CT 06340, USA

${ }^{\mathrm{d}}$ Department of Cell Biology \& Physiology, Neuroscience Center, University of North Carolina, Chapel Hill, NC 27599, USA

\section{Abstract}

The phosphodiesterases (PDEs) are a superfamily of enzymes that regulate spatio-temporal signaling by the intracellular second messengers cAMP and cGMP. PDE2A is expressed at high levels in the mammalian brain. To advance our understanding of the role of this enzyme in regulation of neuronal signaling, we here describe the distribution of PDE2A in the rat brain. PDE2A mRNA was prominently expressed in glutamatergic pyramidal cells in cortex, and in pyramidal and dentate granule cells in the hippocampus. Protein concentrated in the axons and nerve terminals of these neurons; staining was markedly weaker in the cell bodies and proximal dendrites. In addition, in both hippocampus and cortex, small populations of non-pyramidal cells, presumed to be interneurons, were strongly immunoreactive. PDE2A mRNA was expressed in medium spiny neurons in neostriatum. Little immunoreactivity was observed in cell bodies, whereas dense immunoreactivity was found in the axon tracts of these neurons and their terminal regions in globus pallidus and substantia nigra pars reticulata. Immunostaining was dense in the medial habenula, but weak in other diencephalic regions. In midbrain and hindbrain, immunostaining was restricted to discrete regions of the neuropil or clusters of cell bodies. These results suggest that PDE2A may modulate cortical, hippocampal and striatal networks at several levels. Preferential distribution of PDE2A into axons and terminals of the principal neurons suggests roles in regulation of axonal excitability or transmitter release. The enzyme is also in

\footnotetext{
(C) 2012 IBRO. Published by Elsevier Ltd. All rights reserved.

*Corresponding author. Address: Mnemosyne Pharmaceuticals Inc., One Davol Square, Suite 200, Providence, RI 02903, USA. Tel: +1-860-572-1343; fax: +1-401-831-0022.

TPresent address: Critical Path Institute, 1730 East River Road, Tucson, AZ 85718-5893, USA.

†Present address: University of South Carolina School of Medicine, Department of Pharmacology, Physiology \& Neuroscience, VA Building 1, Third Floor, Columbia, SC 29208, USA.

§Present address: Selventa, One Alewife Center, Cambridge, MA 02140, USA.
} 
forebrain interneurons, and in mid- and hindbrain neurons that may modulate forebrain networks and circuits.

\section{Keywords}

phosphodiesterase 2A; PDE2A; immunohistochemistry; cortex; hippocampus; striatum

\section{Introduction}

The cyclic nucleotides cAMP and cGMP are ubiquitous intracellular second messengers that regulate a remarkable diversity of biological processes. Utilization of only two molecules for diverse functions is dependent upon the ability to maintain the spatial and temporal specificity of these signals. Key to this specificity is the phosphodiesterase (PDE) superfamily of enzymes, which hydrolyze cAMP and cGMP to terminate their action (Conti and Beavo, 2007; Omori and Kotera, 2007). Eleven families of mammalian PDEs are encoded by 21 genes that, through alternative RNA splicing, give rise to well over 60 isoforms that differ in substrate specificity and allosteric regulation. Each PDE gene has a unique expression pattern at the tissue and cellular level (Bingham et al., 2006).

Furthermore, the subcellular distribution of isoforms is restricted and may be subject to local regulation, as has been shown for PDE4 (Lynch et al., 2006). Thus, the precise localization of specific PDEs may be crucial for control of cyclic nucleotide signaling. PDE families in the brain exhibit distinct but overlapping regional and circuit distributions (Menniti et al., 2006; Lakics et al., 2010; Kelly, 2012); the distribution of specific isoforms can provide important clues regarding their roles in brain function. The goal of the present study was to identify the cellular and subcellular distribution of PDE2A, an isoform notable for its exceptionally high expression in the brain.

PDE2A is a dual substrate enzyme, capable of degrading both cGMP and cAMP (Sonnenburg et al., 1991; Rosman et al., 1997). The enzymatic activity of PDE2A may be regulated allosterically by cGMP binding to an N-terminal GAF (cGMP-specific and -

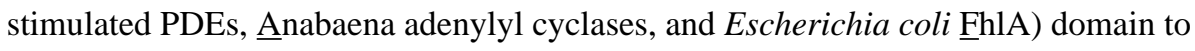
increase hydrolytic activity (Stroop and Beavo, 1991; Juilfs et al., 1999). This provides a potential mechanism by which PDE2A may exert regulatory feedback inhibition of cGMP signaling, as well as cross-talk regulatory inhibition of cAMP signaling by cGMP (MacFarland et al., 1991; Stroop and Beavo, 1991). In a survey of the expression pattern of PDE2A protein in multiple mammalian species (Stephenson et al., 2009), we found that by far the highest levels of protein were in the brain, as suggested by previous data on mRNA expression (Sonnenburg et al., 1991; Rosman et al., 1997; Van Staveren et al., 2003). In our 2009 study, we reported that the expression pattern of PDE2A in the brain is generally consistent across species from rodent to primate. We here present a more detailed analysis of the distribution of this enzyme in the brain, using rat as a representative species. 


\section{Experimental Procedures}

Animals

Crl:CD(SD)IGS BR rats (strain code 001) were obtained from Charles River Laboratories (Kingston, NY, USA). All rats used in this study were housed in a facility accredited by the Association for Assessment and Accreditation of Laboratory Animal Care International, and were used in accordance with an approved animal care and use protocol, the Institute for Laboratory Animal Research Guide for the Care and Use of Laboratory Animals (National Research Council, 1996), and all applicable regulations.

\section{In situ hybridization}

Autoradiographic in situ hybridization with ${ }^{35} \mathrm{~S}$-labeled oligonucleotide antisense probes was conducted as previously described (Kelly and Deadwyler, 2002; Kelly et al., 2010). Three distinct probes specific to unique sequences in PDE2A were analyzed; all showed overlapping patterns of mRNA expression. For the data presented here, the oligonucleotide probe corresponding to base pairs 1612-1573 of PDE2A was chosen for a detailed analysis (NM_001143847.1; Antisense: 5-

GGGATGTTCAGGATCTGGCCCGTGGTCGCCACGTGGCC CG-3'). Rats were euthanized with carbon dioxide gas, and exsanguinated; their brains were rapidly frozen. Sections of $20 \mathrm{~lm}$ were cut, post-fixed, defatted, and dehydrated, followed by incubation with the ${ }^{35} \mathrm{~S}$-labeled oligonucleotide probe. Slides were apposed to film for 7 days, and images acquired on a high-resolution digital scanner. Similar patterns of hybridization were observed in mouse tissue with an additional antisense/sense probe pair corresponding to nucleotides 1820-1781 of NM_001143848 (M. P. Kelly, unpublished observation). Sense probes used in a similar manner yielded no specific hybridization signal.

\section{Immunohistochemistry}

The procedures were as described previously (Stephenson et al., 2009). Rats were euthanized with a lethal dose of sodium pentobarbital and perfused transcardially with phosphate buffer followed by $4 \%$ buffered depolymerized paraformaldehyde. Brains were post-fixed by immersion in the same fixative, processed according to established protocols, and embedded in paraffin; 5-1m sections were cut and deposited onto charged glass slides. Two rats were used for the immunohistochemical mapping study. An additional six rats were used to assess PDE2A immunoreactivity in specific regions of interest, and to evaluate the expression of PDE2A relative to that for microtubule-associated protein 2 (MAP2). All immunohistochemical procedures were performed on an autostainer (Dako North America, Inc., Carpinteria, CA, USA) to ensure consistency across slides. One series of slides from the immunohistochemical mapping study was stained with Cresyl Violet to assess cytoarchitecture.

Antibodies-The PDE2A antibody used was PD2A-101AP obtained from FabGennix Inc. (Frisco, TX, USA). This rabbit polyclonal is directed against an 18 amino acid sequence from the C terminal of PDE2A (aa909-926, Ensemble peptide ID ENSP00000334910) that is conserved across species and is not present in other PDE family members. This antibody was characterized extensively in our previous study (Stephenson et al., 2009), which 
reported that: (1) PD2A-101AP recognized a single band of the appropriate molecular weight of $\sim 100 \mathrm{kDa}$ in brain extracts in Western blot analyses, (2) anti-PDE2A staining of rodent brain tissue was absent following pre-adsorption with PDE2A antigenic blocking peptide (P-PD2A100, FabGennix), (3) no staining was observed in fetal brain tissue from PDE2A-specific knockout mice, and (4) identical staining patterns were observed with a monoclonal antibody made against a different portion of the PDE2A protein (Stephenson et al., 2007).

A mouse monoclonal antibody specific for MAP2 was used to study co-localization with PDE2A by dual fluorescence immunohistochemistry. HM-2 (Sigma Aldrich, St. Louis, MO, USA) was raised against rat MAP2; it is reported to recognize all isoforms of this protein (manufacturer's information).

Immunoperoxidase staining-To expose antigenic sites, tissue sections were heated in a Biocare Decloaking Chamber (Biocare Medical, Concord, CA, USA) to $120^{\circ} \mathrm{C}$ at $12-15$ psi for $30 \mathrm{~s}$ followed by a gradual cool down to $85^{\circ} \mathrm{C}$ in Citra Antigen Retrieval pH 6 (Biogenex, San Ramon, CA, USA). Immunostaining was performed by incubating tissues with anti-PDE2A at a dilution of 1:100 for $60 \mathrm{~min}$ at room temperature. Rabbit IgG (Vector Laboratories, Burlingame, CA, USA) was used as negative control, at the same concentration as anti-PDE2A. Antibody binding sites were detected by incubating tissues with a biotinylated secondary goat anti-rabbit antibody (Vector Laboratories) at a concentration of 1:150 for 45 min followed by 30-min incubation with Elite ${ }^{\circledR} \mathrm{ABC}$ (Vector Laboratories). Dako Liquid DAB+ (Vector Laboratories) was used to visualize PDE2A immunoreactivity. Mayer's hematoxylin (Dako) was used as a counterstain.

Double-label immunofluorescence-The comparative distribution of PDE2A and MAP2 was analyzed by confocal fluorescence microscopy. To expose antigenic sites, tissue sections were heated as above in Citra Antigen Retrieval pH 6. PDE2A antibody (1:100) was co-incubated with anti-MAP2 (1:20,000) antibody for $60 \mathrm{~min}$. To detect PDE2A, a biotinylated goat anti-rabbit secondary antibody was applied at 1:150 for 45 min followed by incubation with streptavidin Alexa 488 (Invitrogen, Carlsbad, CA, USA) at 1:400 for 30 min. MAP2 antibody was detected by incubating with a goat anti-mouse Alexa 568 (Invitrogen) secondary antibody at 1:400 for $30 \mathrm{~min}$. All sections were mounted with Vectashield (Vector Laboratories) to delay fading, and DAPI was present as a counterstain to identify cell nuclei (not shown).

Microscopy-All stained slides were examined qualitatively using standard microscopy. Images of immunoperoxidase-stained sections were acquired using an Aperio Scanscope XT system (Aperio Technologies, Vista, CA, USA). Digital images were captured via a 1D CCD line scan under constant exposure and light settings. For each marker, the area of interest was specified and autofocus points were manually indicated on each slide. All slides were then scanned in the automated one-touch mode. Digital images were stored in the svs format (compression quality $=70$ ) and managed in the Spectrum database. High magnification photomicrographs were captured with a Nikon E-100 (Nikon Instruments, Inc., Melville, NY, USA) using a SPOT RT camera. Fluorescently stained sections were analyzed by confocal microscopy on a Leica TCS-SP laser scanning confocal microscope 
(Leica Microsystems Inc., Exton, PA, USA) equipped with argon, krypton, and UV lasers, which allowed excitation at 488, 568, and $358 \mathrm{~nm}$ wavelengths for the detection of Alexa 488, Alexa 568, and DAPI, respectively.

\section{Results \\ PDE2A mRNA}

In situ hybridization demonstrated that message for PDE2A was present at high levels in gray matter throughout the forebrain (Fig. 1; sense control (not shown) revealed no significant signal). PDE2A mRNA was highly expressed in the internal granule layer of the olfactory bulb, and in the anterior olfactory nucleus (Fig. 1A, B). In neocortex, signal was stronger in superficial than deep layers, and was especially intense over the tightly packed layer of neurons in piriform cortex and the pyramidal cell layer of the hippocampus (Fig. 1C-G). Signal was less intense over the granule cells of the dentate gyrus (Fig. 1F, G). Message was intense and diffusely distributed throughout the amygdala and neostriatum, but very weak or absent in globus pallidus (Fig. 1E) and substantia nigra (Fig. 1G). PDE2A mRNA was expressed at very high levels in the medial habenula (Fig. 1F), but at low levels throughout the rest of the diencephalon and mesencephalon (Fig. 1E-G).

\section{PDE2A immunostaining in forebrain}

Immunoperoxidase reaction product was heterogeneously distributed in the rat forebrain, as illustrated in coronal sections at low magnification (Fig. 2). PDE2A was found in the plexiform, granule cell and ependymal layers of the olfactory bulb (Fig. 2A). Immunostaining was especially strong in supragranular layers of neocortex, olfactory tubercle (Fig. 2C), globus pallidus (Fig. 2D), habenula (Fig. 2G), subiculum, and substantia nigra (Fig. $2 \mathrm{H}$ ). Intense staining in the pallidum and substantia nigra was noteworthy, since very little PDE2A message was detected in these regions (Fig. 1E, G). DAB product was essentially absent from a coronal slice exposed to a rabbit $\operatorname{IgG}$ control antibody processed in parallel (Fig. 2F).

\section{Neocortex}

Immunostaining in neocortex was conspicuously laminar, as illustrated for somatosensory cortex in Fig. 3A. PDE2A was at highest density in layer I, extending through the neuropil of layers II-III. Weaker staining was seen in the neuropil of layer V, and low levels of diffuse immunoreactivity were present in layer IV and the innermost cortical region. At higher magnification (Fig. 3B), the neuropil staining appeared granular, suggesting localization to synaptic puncta. Immunostaining was distinctly weaker in the cell bodies and primary dendrites of the large majority of cells relative to the neuropil. From their morphology, these weakly stained cells are likely glutamatergic pyramidal neurons. In favorable cases, the cell body and proximal apical dendrite of pyramidal neurons appeared coated with immunopositive puncta (Fig. 3B, white arrow). Strongly immunopositive cell bodies scattered amongst the numerous weakly stained neurons (Fig. 3C, black arrow) were not of pyramidal morphology and were likely local circuit neurons. 


\section{Hippocampus}

PDE2A immunoreactivity was strong in stratum oriens of CA1, stratum lucidum of CA3 (the region of mossy fiber terminals), and the hilar region of the dentate gyrus (Fig. 4A). Staining in the molecular layer of the dentate gyrus was organized into three sharply defined zones, including a weakly stained inner, moderately stained middle, and strongly stained outer layer (Fig. 4A, C). Immunoreaction was largely excluded from the densely packed cells of the pyramidal cell layer in Ammon's horn and the granule cell layer of dentate gyrus (Fig. 4A-C). Similarly, immunoreaction was weak or undetectable in the proximal dendrites of the pyramidal cells (Fig. 4B). However, scattered densely stained somata were seen in the pyramidal cell layer, particularly in CA3 (Fig. 4A).

The anatomy of the mossy fiber termination in CA3 afforded an opportunity to investigate the subcellular distribution of PDE2A. We used dual-label immunofluorescence confocal microscopy to compare the distribution of PDE2A to that of the dendritic marker MAP2 (Fig. 5). Puncta immunopositive for PDE2A (green channel in Fig. 5A, C) were diffusely distributed throughout most of this region, with discrete areas that contained little or no immunoreactivity. There was virtually no overlap between PDE2A and MAP2 immunoreactivity; in fact, many of the large dendritic shafts defined by MAP2 immunoreactivity corresponded to areas that were devoid of PDE2A (Fig. 5A-C).

\section{Piriform cortex and amygdala}

PDE2A immunostaining was diffusely distributed throughout the neuropil in the piriform cortex (Fig. 6). Diffuse staining was also observed throughout the amygdaloid complex, which merged without obvious border into the caudate nucleus. The exception was the sharply delineated anterior cortical amygdaloid nucleus (ACo), which exhibited stronger immunostaining than the surrounding tissue. Cell bodies throughout the region of the piriform cortex and amygdala exhibited markedly weaker immunoreactivity than the neuropil, as particularly obvious in layer II of piriform cortex. The exception was a band of scattered immunopositive cell bodies running mediolaterally through the amygdaloid complex and then dorsally along its lateral border (arrows, Fig. 6).

\section{Striatum and striatal projections}

PDE2A immunostaining was distributed throughout the neuropil of the neostriatum (Fig.

7A). There was no obvious regional variation in density in either the dorsal/ventral or medial/lateral axis, nor was there evidence of differential density that might suggest preferential localization in a striatal subcompartment. Staining was excluded from the bundles of myelinated fibers that run through the striatum. Immunostaining was markedly stronger in the striatal projection regions of the globus pallidus and substantia nigra pars reticulata than in the neostriatum (Fig. 7). Within substantia nigra, immunostaining was markedly higher in reticulata than in pars compacta (Fig. 7B), and was very weak in the ventral tegmental area. In contrast to the neuropil, somata in neostriatum, globus pallidus and substantia nigra generally showed little or no immunostaining. The interpeduncular nucleus (which receives a projection from the medial habenula) was very densely stained (Fig. 7B). 


\section{Brain stem}

PDE2A immunoreactivity was heterogeneously distributed throughout the midbrain (Fig. 8). Diffuse immunostaining of the neuropil was observed in the external cortex of the inferior colliculus, central gray region, and in the region ventrolateral to the central gray (Fig 8A), and on the ventromedial edge of the section, associated with the pyramidal tract.

Immunoreactivity was observed in cell bodies and neuropil in the dorsal raphe nucleus, as well as dense filamentous staining in the midline just ventral to the stained raphe somata (Fig. 8B). Somatic staining on a background of weakly stained neuropil was seen in the region of the lateral dorsal tegmentum (Fig. 8C, D). Only light staining was seen in the neuropil of the locus coeruleus, and cell bodies in this region were unstained. More caudally, the neuropil associated with the lateral and superior vestibular nuclei was stained, as were the fibers of the pyramidal tract (Fig. 9A).

\section{Cerebellum}

Uniform light staining was observed in the molecular layer of cerebellar cortex (Fig. 9A). At higher magnification, this staining resolved into scattered puncta and thin fibers running perpendicular to the axis of the Purkinje cell layer (Fig. 9B). Purkinje cells stained very lightly (Fig. 9B, arrowhead), whereas a restricted subset of strongly immunopositive smaller interneurons was scattered throughout the molecular and granule cell layers.

\section{Spinal cord}

PDE2A immunoreactivity was mainly confined to gray matter, though staining was also present in the dorsal corticospinal tract (Fig. 10). The highest density of immunostaining was seen in the neuropil of the dorsal horn, especially in laminae I-II. Scattered strongly immunopositive somata were visible throughout the spinal gray.

\section{Vascular staining}

The expression of PDE2A protein associated with blood vessels supplying the brain has been reported previously (Stephenson et al., 2009). We confirmed this observation in the present study; a particularly clear example is visible in Fig. $8 \mathrm{D}$, where arrows point to several strongly immunopositive endothelial cells lining a small arteriole.

\section{Discussion}

The dual substrate phosphodiesterase PDE2A is highly expressed in the brain (Repaske et al., 1993; Yang et al., 1994; van Staveren et al., 2003; Stephenson et al., 2009; Lakics et al., 2010; Kelly, 2012), suggesting a significant role for the enzyme in regulating neuronal signaling, and fostering interest in developing selective pharmacological inhibitors as potential neurotherapeutics (Menniti et al., 2006; Conti and Beavo, 2007; Omori and Kotera, 2007; Schmidt, 2010). Unique insights into this physiology and pharmacology may be gained through detailed mapping of the distribution of PDE2A in the brain. The present study revealed a remarkably complex distribution of PDE2A, which was found to be expressed at varying intensity levels in different neuronal types and circuits throughout the neuraxis. Furthermore, the enzyme was found to be differentially distributed into neuronal subcellular compartments in a cell type-specific manner. These results provide an important 
guide for ongoing investigations into the functions of PDE2A in the brain and in interpreting the effects of pharmacological inhibition of the enzyme on behavior, as discussed below.

PDE2A is most broadly expressed in subsets of glutamatergic principal neurons in the forebrain, as indicated by the distribution of mRNA (van Staveren et al., 2003 and present study). PDE2A mRNA is present in a high percentage of cells throughout neocortex, consistent with expression in the pyramidal neurons that comprise the major neuronal populations in this structure. PDE2A mRNA is also expressed at notably high levels in the majority of principal neurons of allocortex, both in piriform cortex and in the pyramidal cell layer of the hippocampus. PDE2A mRNA is present in the dentate granule cells, but at lower levels than in the hippocampal pyramidal neurons. On the other hand, PDE2A is only weakly expressed or absent in other classes of forebrain glutamatergic neurons. For examples, little or no expression of PDE2A mRNA was observed in thalamus, which contains populations of glutamatergic neurons that project to cortex and striatum, and in the hilus of the hippocampus, which contains the glutamatergic mossy cells (Buckmaster et al., 1996).

The distribution of PDE2A protein in the cortex and hippocampus is consistent with expression by the different classes of glutamatergic neurons that express PDE2A mRNA, if attention is focused on major projections from these neurons. This is especially clear for the hippocampus, where variations in the density of PDE2A immunoreactivity corresponded to distinct axonal tracts. The highest density was found in the subiculum, hilus, and the region of the mossy fiber terminals in CA3, the major projection target of dentate granule cells. In the stratum moleculare of the dentate gyrus, PDE2A was higher in the outer two thirds, corresponding to the terminal zone of perirhinal cortical neurons of the perforant path. In the hippocampus proper, PDE2A staining was notable in the fibers of the alveus, which collects the axons of pyramidal neurons projecting out of the hippocampus via the fimbria/fornix and the axons of CA1 pyramidal neurons projecting to the subiculum. In contrast, PDE2A staining was weak in the majority of cell bodies and proximal dendrites in the hippocampus and dentate gyrus, despite the strong expression of PDE2A mRNA in these neurons.

Taken together, the immunohistochemical analysis of the hippocampus suggests that PDE2A is preferentially distributed to axons and terminals of the glutamatergic projection neurons that express the protein. To further interrogate this hypothesis, we took advantage of the unique anatomy of the dentate granule cell projection giving rise to the mossy fiber terminals that synapse onto dendrites of CA3 pyramidal neurons. In double label immunofluorescence experiments, we found that the dense zones of PDE2A immunoreactivity in this region did not overlap with the dendritic marker, MAP2, indicating that PDE2A is localized selectively to the presynaptic mossy fiber terminals. Other lines of evidence also suggest that PDE2A is predominantly localized to presynaptic terminals in the hippocampus. Using differential centrifugation, Xie et al. (2006) found PDE2A associated with synaptosomes derived from the rat brain. More recently, Russwurm et al. (2009) confirmed an association of PDE2A with synaptosomal membranes from the rat brain, and demonstrated overlap of PDE2A immunoreactivity with the presynaptic protein synaptophysin in primary cultures of rat hippocampal neurons. 
The distribution of PDE2A in neocortex is consistent with localization predominantly in axons and terminals of the principal neurons. PDE2A immunoreactivity was found at highest levels in outer cortical layers, as well as in a band through upper layer V. Lower levels of expression were observed in layer IV and in deep layers V and VI. As in the hippocampus, PDE2A was present at notably lower levels in pyramidal cell bodies and proximal dendrites than in the surrounding neuropil. This pattern suggests that the laminar neuropil staining resides within intracortical axons and terminals emanating from principal neurons in these regions. However, this hypothesis bears further investigation using techniques suited to resolving the location of immunoreactivity at individual synapses. PDE2A immunoreactivity was largely absent from white matter tracts through basal ganglia, and was present at rather low levels in the pyramidal tract in the brainstem and spinal cord, suggesting that PDE2A may be expressed at lower levels in layer V pyramidal neurons that project out of neocortex.

Localization of PDE2A to an axonal/presynaptic compartment in glutamatergic pyramidal neurons positions the enzyme to regulate presynaptic forms of plasticity. In the mossy fiber terminals of CA3, cAMP modifies vesicle release probability during induction of long term potentiation (LTP) (Nicoll and Schmitz, 2005). This form of presynaptic plasticity is also observed at corticostriatal synapses (Nicoll and Schmitz, 2005). cGMP signaling is also implicated in the regulation of presynaptic plasticity (Feil and Kleppisch, 2008). Indeed, PDE2A inhibition is reported to potentiate the induction of LTP at the Schaeffer collateral/CA1 synapse in slices of the rat hippocampus (Boess et al., 2004). It will be of interest to further investigate PDE2A localization to presynaptic glutamatergic terminals throughout the cortex and hippocampus, the mechanisms that underlie such localization (Russwurm et al., 2009), and to define the role through which the enzyme may regulate synaptic plasticity.

In contrast to the observation that the majority of neuronal cell bodies in the forebrain had low levels of PDE2A staining relative to the neuropil, several distinct populations of cells were observed with strong somatic immunostaining. These cells were particularly prevalent in the $\mathrm{CA} 3$ region of the hippocampus and in a band scattered along the ventral border of the lateral and central amygdaloid nucleus. Such cells were also scattered throughout the neocortex. From their non-pyramidal shape, we speculate that these are local circuit neurons. Consistent with this hypothesis, we noted PDE2A-containing puncta lining cell bodies and proximal dendrites of pyramidal neurons in neocortex. The large majority of synaptic contacts on cortical pyramidal neuron cell bodies are GABAergic (Jones and Hendry, 1984; Markram et al., 2004), suggesting the presence of PDE2A in such GABAergic terminals.

The other major cell type expressing PDE2A in the forebrain was found to be the striatal medium spiny neurons (MSNs). PDE2A mRNA was detected in most cells throughout the striatal complex, in agreement with previous studies (van Staveren et al., 2003). This mRNA distribution can be accounted for by expression in GABAergic MSNs, which comprise over 90\% of striatal neurons (Albin et al., 1989; Wilson, 2004). Moderate levels of PDE2A immunoreactivity were distributed throughout the neuropil of the neostriatum, whereas somata showed little evidence of immunostaining. In contrast, especially strong immunostaining was observed in the globus pallidus and substantia nigra, pars reticulata 
( $\mathrm{SNr}$ ). This is likely to arise from the MSN axons that terminate in these regions, since neither globus pallidus nor substantia nigra contained substantial levels of PDE2A mRNA. These findings suggest that PDE2A is also preferentially distributed to axons and terminals of striatal projection neurons.

Two subtypes of MSNs, comprising the direct and indirect output pathways of the striatum, terminate in the substantia nigra or globus pallidus, respectively (Albin et al., 1989; Reiner et al., 2010). The fact that PDE2A is present at equivalent levels in both of these projection regions indicates that the enzyme is expressed by both MSN subtypes, suggesting that PDE2A may regulate similar signaling cascades among all MSN subtypes. However, it has recently been reported that PDE2A mediates cross-talk between cAMP and cGMP signaling in response to dopamine D1 receptor activation (Lin et al., 2010), whereas PDE10A, another dual substrate PDE highly expressed by all MSNs (Seeger et al., 2003), preferentially regulates excitability in dopamine D2 receptor-expressing MSNs (Threlfell et al., 2009). Apparently, there must be mechanisms to segregate signaling by these PDEs in the two MSN subpopulations, despite uniform expression. The mechanisms that underlie this differential regulation are clearly of interest and bear further study.

In contrast to its strong expression in the forebrain, PDE2A is expressed at generally lower levels in midbrain, hindbrain, cerebellum, and spinal cord. A notable exception is the medial habenula. This discrete group of neurons contains high levels of PDE2A mRNA, and extremely dense PDE2A staining in the somata, axons within the fasiculus retroflexus, and terminals in the interpeduncular nucleus (Herkenham and Nauta, 1979). The substantial PDE2A immunoreactivity in raphe nuclei, but not locus coeruleus, suggests that the enzyme may play a role in serotonergic, but not noradrenergic, regulation. The distribution of PDE2A in the spinal cord is consistent with a role in pain modulation.

The high level of PDE2A expression in the brain has led to interest in selective inhibitors as potential therapeutic agents for CNS disorders (Menniti et al., 2006; Schmidt, 2010). PDE2A inhibition has been found to affect performance on cognitive behavioral tasks in rodents (Boess et al., 2004; Rutten et al., 2007; Domeklopacinska and Strosznajder, 2008; Rodefer et al., 2011) and in tasks that measure behaviors related to anxiety and depression (Masood et al., 2008, 2009). We speculate that the cognitive effects may reflect a role of the enzyme in the regulation of cortical and hippocampal glutamatergic transmission and plasticity. The PDE2A expression in putative GABAergic interneurons suggests that inhibitors may also impact network regulation. The expression of PDE2A in amygdala and putative serotonergic raphe neurons is noteworthy given the effects of PDE2A inhibition in animal models of depression and anxiety. The high expression of PDE2A in striatum suggests that it will be of interest to examine the behavioral effects of PDE2A inhibition in animal models sensitive to perturbation of striatal function, such as locomotor activity and addiction models; likewise, the very high levels of PDE2A in the habenulo-interpeduncular pathway may be relevant for response to aversive stimuli and nicotine dependence (Fowler and Kenny, 2012).

In summary, the present study provides a detailed map of PDE2A expression throughout the neuroaxis. This information provides an anatomical base for future studies of the signaling 
cascades regulated by PDE2A at the cellular levels, and how such regulation is integrated over complex circuits. Neuroanatomical questions that remain include further investigation of the extent to which the enzyme is preferentially distributed into axons and terminals in pyramidal neurons and MSNs, the phenotype(s) of the putative GABAergic interneurons expressing the enzyme, and the identity of PDE2A-positive cell bodies and terminals outside of the forebrain. An important challenge will be to determine how the behavioral effects of systemically administered PDE2A inhibitors reflect effects summed over the complex distribution of the enzyme throughout the CNS. Harnessing this information may identify novel therapeutic uses for compounds that modulate PDE2A activity.

\section{Acknowledgments}

We thank Wilma C. G. van Staveren (Institute of Interdisciplinary Research (IRIBHM), Université Libre de Bruxelles, Faculty of Medicine, Campus Erasme, 808 Route de Lennik, B-1070 Brussels, Belgium) for early input into this study.

\section{References}

Albin RL, Young AB, Penney JB. The functional anatomy of basal ganglia disorders. Trends Neurosci. 1989; 12(10):366-375. [PubMed: 2479133]

Bingham J, Sudarsanam S, Srinivasan S. Profiling human phosphodiesterase genes and splice isoforms. Biochem Biophys Res Commun. 2006; 350(1):25-32. [PubMed: 16987497]

Boess FG, Hendrix M, van der Staay FJ, Erb C, Schreiber R, van Staveren W, de Vente J, Prickaerts J, Blokland A, Koenig G. Inhibition of phosphodiesterase 2 increases neuronal cGMP, synaptic plasticity and memory performance. Neuropharmacology. 2004; 47(7):1081-1092. [PubMed: 15555642]

Buckmaster PS, Wenzel HJ, Kunkel DD, Schwartzkroin PA. Axon arbors and synaptic connections of hippocampal mossy cells in the rat in vivo. J Comp Neurol. 1996; 366:270-292.

Conti M, Beavo J. Biochemistry and physiology of cyclic nucleotide phosphodiesterases: essential components in cyclic nucleotide signaling. Ann Rev Biochem. 2007; 76(1):481-511. [PubMed: 17376027]

Domeklopacinska K, Strosznajder J. The effect of selective inhibition of cyclic GMP hydrolyzing phosphodiesterases 2 and 5 on learning and memory processes and nitric oxide synthase activity in brain during aging. Brain Res. 2008; 1216:68-77. [PubMed: 18499090]

Feil, R.; Kleppisch, T. NO/cGMP-dependent modulation of synaptic transmission. In: Sudhof, TC.; Starke, K., editors. Pharmacology of neurotransmitter release. Berlin, Heidelberg: Springer-Verlag; 2008. p. 529-560.

Fowler CD, Kenny PJ. Habenular signaling in nicotine reinforcement. Neuropsychopharmacology. 2012; 37(1):306-307. [PubMed: 22157872]

Herkenham M, Nauta WJ. Efferent connections of the habenular nuclei in the rat. J Comp Neurol. 1979; 187(1):19-47. [PubMed: 226566]

Jones, EG.; Hendry, SHC. Basket cells. In: Peters, AJE., editor. Cerebral cortex: cellular components of the cerebral cortex. New York: Plenum Press; 1984. p. 309-334.

Juilfs D, Soderling S, Burns F, Beavo J. Cyclic GMP as substrate and regulator of cyclic nucleotide phosphodiesterases (PDEs). Rev Physiol Biochem Pharmacol. 1999; 135(1):67-104. [PubMed: 9932481]

Kelly, MP. Putting together the pieces of phosphodiesterase distribution patterns in the brain: a jigsaw puzzle of cyclic nucleotide regulation. In: Brandon, NJ.; West, AR., editors. Phosphodiesterases in the CNS. New York: John Wiley \& Sons, Inc; 2012.

Kelly MP, Deadwyler SA. Acquisition of a novel behavior induces higher levels of Arc mRNA than does overtrained performance. Neuroscience. 2002; 110(4):617-626. [PubMed: 11934470] 
Kelly MP, Logue SF, Brennan J, Day JP, Lakkaraju S, Jiang L, Zhong X, Tam M, Sukoff Rizzo SJ, Platt BJ, Dwyer JM, Neal S, Pulito VL, Agostino MJ, Grauer SM, Navarra RL, Kelley C, Comery TA, Murrills RJ, Houslay MD, Brandon NJ. Phosphodiesterase 11A in brain is enriched in ventral hippocampus and deletion causes psychiatric disease-related phenotypes. Proc Natl Acad Sci U S A. 2010; 107(18):8457-8462. [PubMed: 20404172]

Lakics V, Karran EH, Boess FG. Quantitative comparison of phosphodiesterase mRNA distribution in human brain and peripheral tissues. Neuropharmacology. 2010; 59(6):367-374. [PubMed: 20493887]

Lin DTS, Fretier P, Jiang C, Vincent SR. Nitric oxide signaling via cGMP-stimulated phosphodiesterase in striatal neurons. Synapse. 2010; 64(6):460-466. [PubMed: 20175220]

Lynch, MJ.; Hill, EV.; Houslay, MD. Intracellular targeting of phosphodiesterase-4 underpins compartmentalized cAMP signaling. In: Gerald, PS., editor. Current topics in developmental biology. Academic Press; 2006. p. 225-259.

MacFarland R, Zelus B, Beavo J. High concentrations of a cGMP-stimulated phosphodiesterase mediate ANP- induced decreases in cAMP and steroidogenesis in adrenal glomerulosa cells. J Biol Chem. 1991; 266(1):136-142. [PubMed: 1845962]

Markram H, Toledo-Rodriguez M, Wang Y, Gupta A, Silberberg G, Wu C. Interneurons of the neocortical inhibitory system. Nat Rev Neurosci. 2004; 5(10):793-807. [PubMed: 15378039]

Masood A, Nadeem A, Mustafa SJ, O'Donnell JM. Reversal of oxidative stress-induced anxiety by inhibition of phosphodiesterase-2 in mice. J Pharmacol Exp Ther. 2008; 326(2):369-379. [PubMed: 18456873]

Masood A, Huang Y, Hajjhussein H, Xiao L, Li H, Wang W, Hamza A, Zhan CG, O'Donnell JM. Anxiolytic effects of phosphodiesterase-2 inhibitors associated with increased cGMP signaling. J Pharmacol Exp Ther. 2009; 331(2):690-699. [PubMed: 19684253]

Menniti FS, Faraci WS, Schmidt CJ. Phosphodiesterases in the CNS: targets for drug development. Nat Rev Drug Discov. 2006; 5(8):660-670. [PubMed: 16883304]

Nicoll RA, Schmitz D. Synaptic plasticity at hippocampal mossy fibre synapses. Nat Rev Neurosci. 2005; 6(11):863-876. [PubMed: 16261180]

Omori K, Kotera J. Overview of PDEs and their regulation. Circ Res. 2007; 100(3):309-327. [PubMed: 17307970]

Paxinos, G.; Watson, C. The rat brain in stereotaxic coordinates. San Diego: Academic Press; 1997.

Reiner A, Hart NM, Lei W, Deng Y. Corticostriatal projection neurons - dichotomous types and dichotomous functions. Front Neuroanat. 2010; 4:142. [PubMed: 21088706]

Repaske DR, Corbin JG, Conti M, Goy MF. A cyclicGMP-stimulated cyclic nucleotide phosphodiesterase gene is highly expressed in the limbic system of the rat brain. Neuroscience. 1993; 56:673-686. [PubMed: 8305078]

Rodefer JS, Saland SK, Eckrich SJ. Selective phosphodiesterase inhibitors improve performance on the ED/ID cognitive task in rats. Neuropharmacology. 2011; 62(3):1182-1190. [PubMed: 21856317]

Rosman GJ, Martins TJ, Sonnenburg WK, Beavo JA, Ferguson K, Loughney K. Isolation and characterization of human cDNAs encoding a cGMP-stimulated $3^{\prime}, 5^{\prime}$-cyclic nucleotide phosphodiesterase. Gene. 1997; 191(1):89-95. [PubMed: 9210593]

Russwurm C, Zoidl G, Koesling D, Russwurm M. Dual acylation of PDE2A splice variant 3: targeting to synaptic membranes. J Biol Chem. 2009; 284(38):25782-25790. [PubMed: 19632989]

Rutten K, Prickaerts J, Hendrix M, Vanderstaay F, Sik A, Blokland A. Time-dependent involvement of cAMP and cGMP in consolidation of object memory: studies using selective phosphodiesterase type 2, 4 and 5 inhibitors. Eur J Pharmacol. 2007; 558(1-3):107-112. [PubMed: 17207788]

Schmidt CJ. Phosphodiesterase inhibitors as potential cognition enhancing agents. Curr Top Med Chem. 2010; 10:222-230. [PubMed: 20166957]

Seeger TF, Bartlett B, Coskran TM, Culp JS, James LC, Krull DL, Lanfear J, Ryan AM, Schmidt CJ, Strick CA, Varghese AH, Williams RD, Wylie PG, Menniti FS. Immunohistochemical localization of PDE10A in the rat brain. Brain Res. 2003; 985(2):113-126. [PubMed: 12967715] 
Sonnenburg WK, Mullaney PJ, Beavo JA. Molecular cloning of a cyclic GMP-stimulated cyclic nucleotide phosphodiesterase cDNA. Identification and distribution of isozyme variants. J Biol Chem. 1991; 266(26):17655-17661. [PubMed: 1654333]

Stephenson, DT.; Coskran, TM.; Morton, DG.; Wilhelms, MB.; Ryan, AM.; Finley, J.; Nelson, R.; Tate, BA.; Menniti, FS.; Schmidt, CJ.; Kleiman, RJ. PDE2A is localized to amyloid plaques in human Alzheimer's disease brain and in transgenic amyloid overexpressing mice; Society for Neuroscience 37th Annual Meeting; Nov. 3-7, 2007; San Diego, CA. 2007. p. 152110/Q116

Stephenson D, Coskran T, Wilhelms M, Adamowicz W, O'Donnell M, Muravnick K, Menniti F, Kleiman R, Morton D. Immunohistochemical localization of PDE2A in multiple mammalian species. J Histochem Cytochem. 2009; 57:933-949. [PubMed: 19506089]

Stroop S, Beavo J. Structure and function studies of the cGMP-stimulated phosphodiesterase. J Biol Chem. 1991; 266(35):23802-23809. [PubMed: 1721055]

Threlfell S, Sammut S, Menniti FS, Schmidt CJ, West AR. Inhibition of phosphodiesterase 10A increases the responsiveness of striatal projection neurons to cortical stimulation. J Pharmacol Exp Ther. 2009; 328(3):785-795. [PubMed: 19056933]

Van Staveren WCG, Steinbusch HWM, Markerink-Van Ittersum M, Repaske DR, Goy MF, Kotera J, Omori K, Beavo JA, De Vente J. MRNA expression patterns of the cGMP-hydrolyzing phosphodiesterases types 2, 5, and 9 during development of the rat brain. J Comp Neurol. 2003; 467(4):566-580. [PubMed: 14624489]

Wilson, CJ. Basal ganglia. In: Shepherd, GMG., editor. The synaptic organization of the brain. New York: Oxford University Press; 2004. p. 361-415.

Xie Z, Adamowicz W, Eldred W, Jakowski A, Kleiman R, Morton D, Stephenson D, Strick C, Williams R, Menniti F. Cellular and subcellular localization of PDE10A, a striatum-enriched phosphodiesterase. Neurosci. 2006; 139(2):597-607.

Yang Q, Paskind M, Bolger G, Thompson WJ, Repaske DR, Cutler LS, Epstein PM. A novel cyclicGMP stimulated phosphodiesterase from rat brain. Biochem Biophys Res Commun. 1994; 205:1850-1858. [PubMed: 7811274]

\section{Abbreviations}

$\begin{array}{ll}\text { DAPI } & \text { 4',6-diamidino-2-phenylindole }^{\prime} \\ \text { MAP2 } & \text { microtubule-associated protein } 2 \\ \text { MSNs } & \text { striatal medium spiny neurons } \\ \text { PDE } & \text { phosphodiesterase }\end{array}$




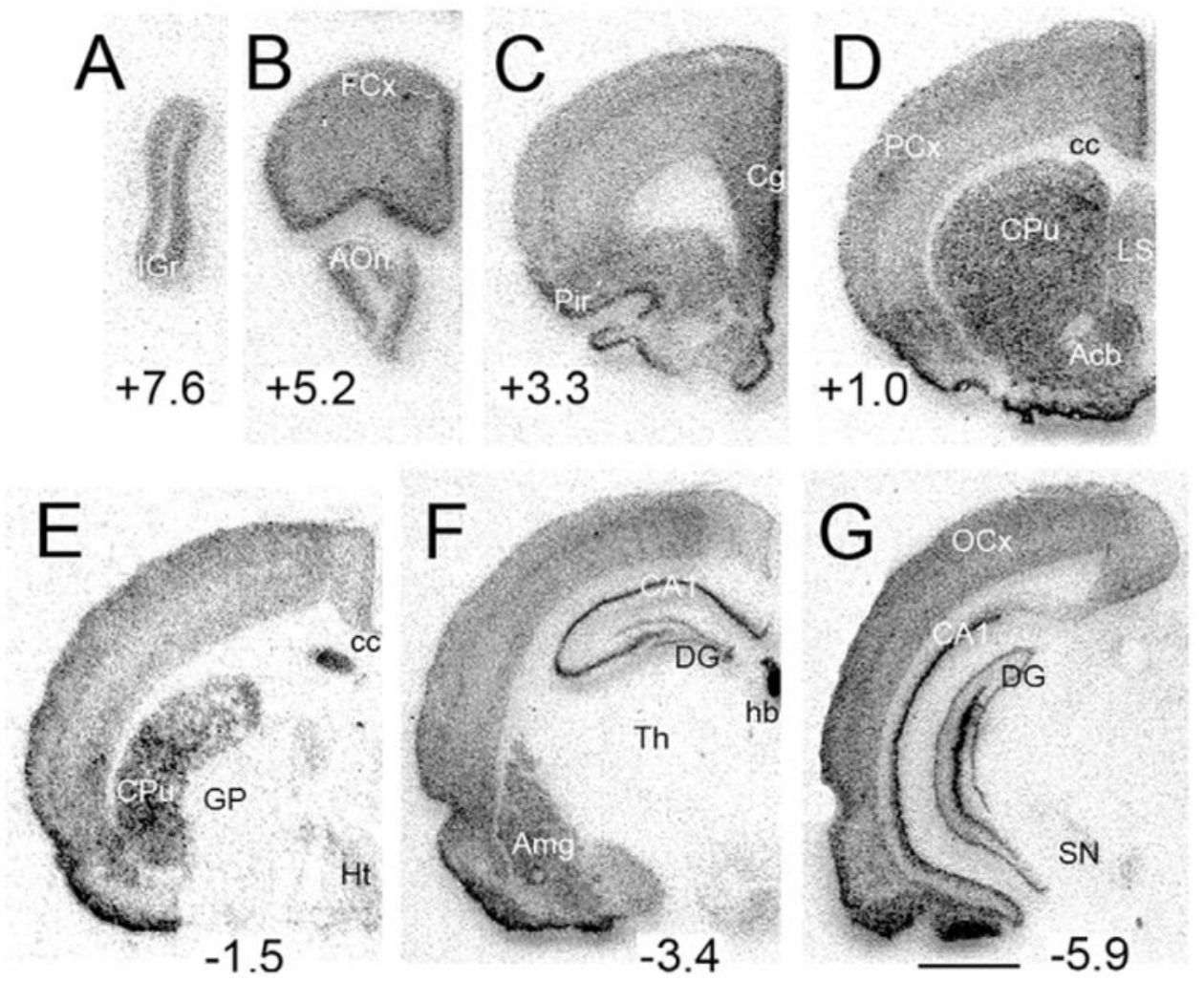

Fig. 1.

Distribution of PDE2A mRNA in coronal sections of rat brain, determined by in situ hybridization. Hybridization signal is black. Numbers at bottom of panels are distance from bregma, according to the atlas of Paxinos and Watson (1997). Message is high in cortical regions, striatum, and the habenula. Abbreviations used in the figures: A, cerebral aqueduct; ac, anterior commissure; Acb, n. accumbens; ACo, anterior cortical amygdaloid n; Amg, amygdaloid complex; AOn, anterior olfactory n.; BLA, basolateral amygdaloid n; CB, cerebellum; CC, central canal; cc, corpus callosum; $\mathrm{Cg}$, cingulate cortex; $\mathrm{Ce}$, central amygdaloid n; $\mathrm{CP}$, caudate-putamen; $\mathrm{CPu}$, caudate n. and putamen; dc, dorsal columns; dcs, dorsal corticospinal tract; DG, dentate gyrus; DR, dorsal raphe; FCx, frontal cortex; GC, granule cell layer; GP, globus pallidus; GPe; external part of globus pallidus; hb, habenula; $\mathrm{Ht}$, hypothalamus; IC, inferior colliculus; IGr, internal granule cell layer of olfactory bulb; In, interpeduncular nucleus; LL, lateral lemniscus; LS, lateral septal n.; M, molecular layer; MR, median raphe; MVe, medial vestibular nucleus; OCx, occipital cortex; Opt, optic tract; PC, Purkinje cell layer; PCx, parietal cortex; Pir, piriform cortex; Pl, plexiform layer of olfactory bulb; Py, pyramidal cell layer; RF, rhinal fissure; SG, substantia gelatinosa; SL, stratum lucidum; SN, substantia nigra; SNc, substantia nigra, pars compacta; SNr, substantia nigra, pars reticulata; $\mathrm{SO}$, stratum oriens; $\mathrm{SR}$, stratum radiatum; Th, thalamus; 3v, 3rd ventricle; VH, ventral horn. Scale bar in $\mathrm{G}=2.5 \mathrm{~mm}$. 

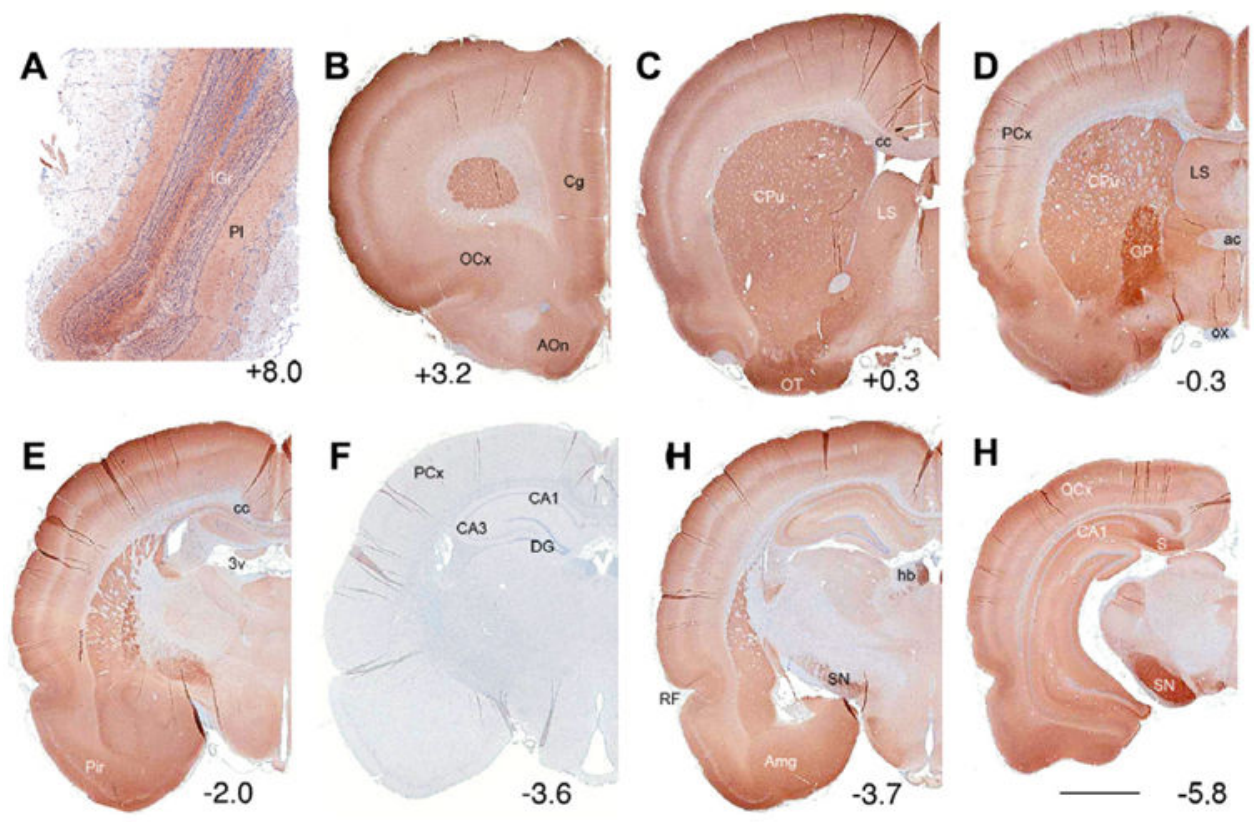

Fig. 2.

Distribution of PDE2A immunoreactivity in coronal sections of rat brain, as determined by immunohistochemistry. Immunoreaction is brown; blue is counterstain. Numbers at bottom of panels are distance from bregma. Primary antibody was replaced by control IgG in F. Immunostaining is especially prominent in olfactory tubercule, globus pallidus, habenula, and substantia nigra (see text). Scale bar (panel H): $1 \mathrm{~mm}$ for panel A, $2 \mathrm{~mm}$ for all other panels. (For interpretation of the references to color in this figure legend, the reader is referred to the web version of this article.) 

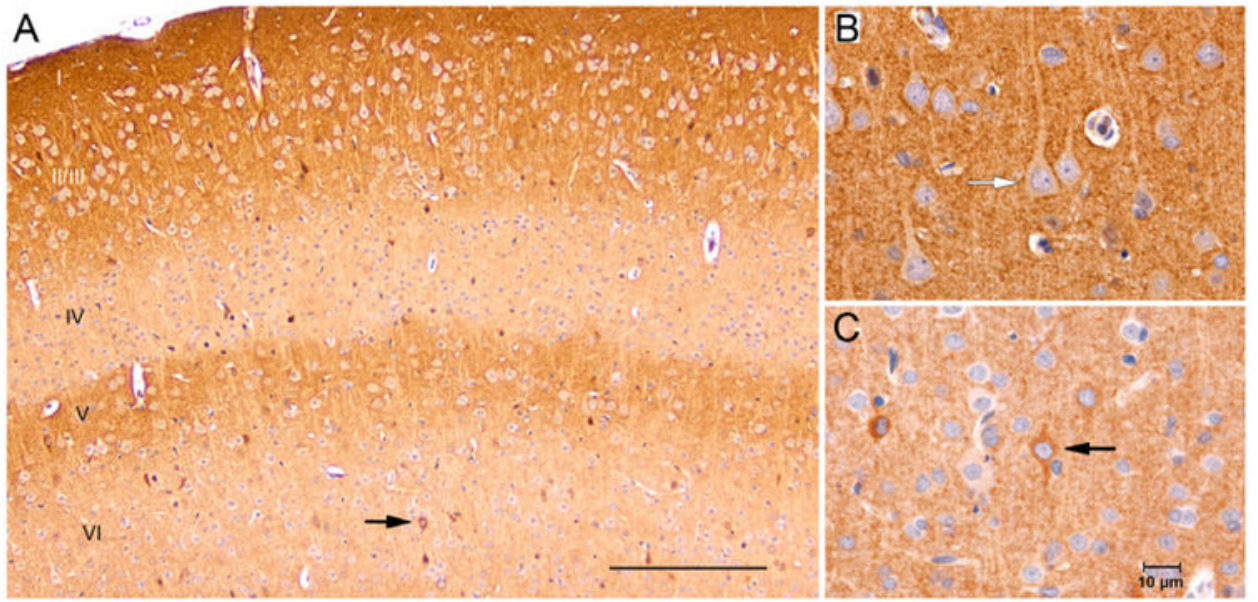

Fig. 3.

Distribution of PDE2A immunostaining in somatosensory cortex (approximately $1 \mathrm{~mm}$ caudal to bregma). (A) Staining is strongest in superficial layers (cortical layers are denoted by Roman numerals). Black arrow points to a strongly stained non-pyramidal cell body in layer VI. (B) Higher magnification micrograph from II/III. Immunostaining is generally weaker in pyramidal cell bodies than in the surrounding neuropil. White arrow points to the pyramidal cell where granular staining appears to line cell body and the apical dendrite. (C) Black arrow points to a strongly immunopositive non-pyramidal cell located in upper layer IV of somatosensory cortex. Scale bars: Panel A $=500 \mu \mathrm{m}$; panel C (for B, C) $=10 \mu \mathrm{m}$. 


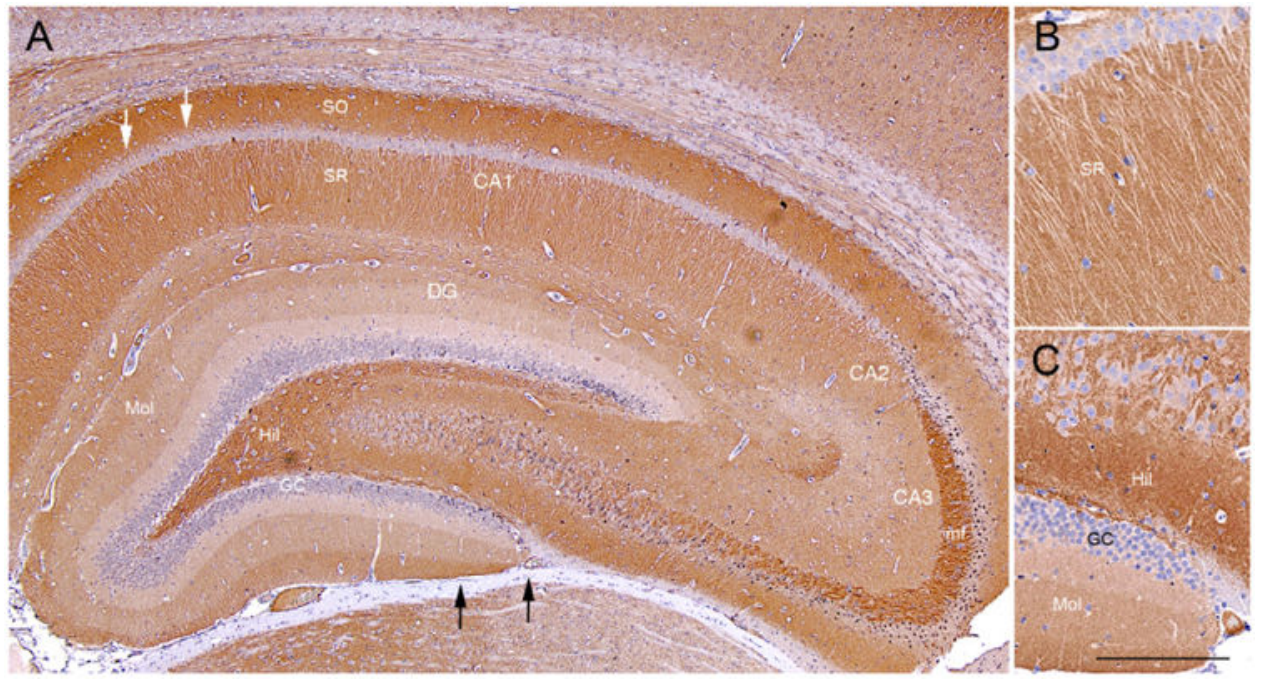

Fig. 4.

PDE2A immunoreactivity in hippocampus. (A) Low magnification view; staining is conspicuous in stratum oriens of CA1, the terminal field of mossy fibers in CA3, and the hilus of dentate gyrus. White and black arrows indicate the areas depicted in $\mathrm{B}$ and $\mathrm{C}$ (which were from different material). (B) Higher magnification view of CA1. Very weak staining in cell bodies and primary dendrites of hippocampal pyramidal neurons contrasts with stronger diffuse staining in the neuropil of stratum radiatum. (C) Detail from dentate gyrus. Note strong immunostaining in hilus, sublaminar pattern of staining in the molecular layer, and the low density of immunoreactivity in the cell bodies of granule cells. Scale bar in $\mathrm{C}=500$ $\mu \mathrm{m}$ (for panel A); $250 \mu \mathrm{m}$ (for B, C). Panel A is revised from a figure previously published (Stephenson et al., 2009), and is used with permission. 


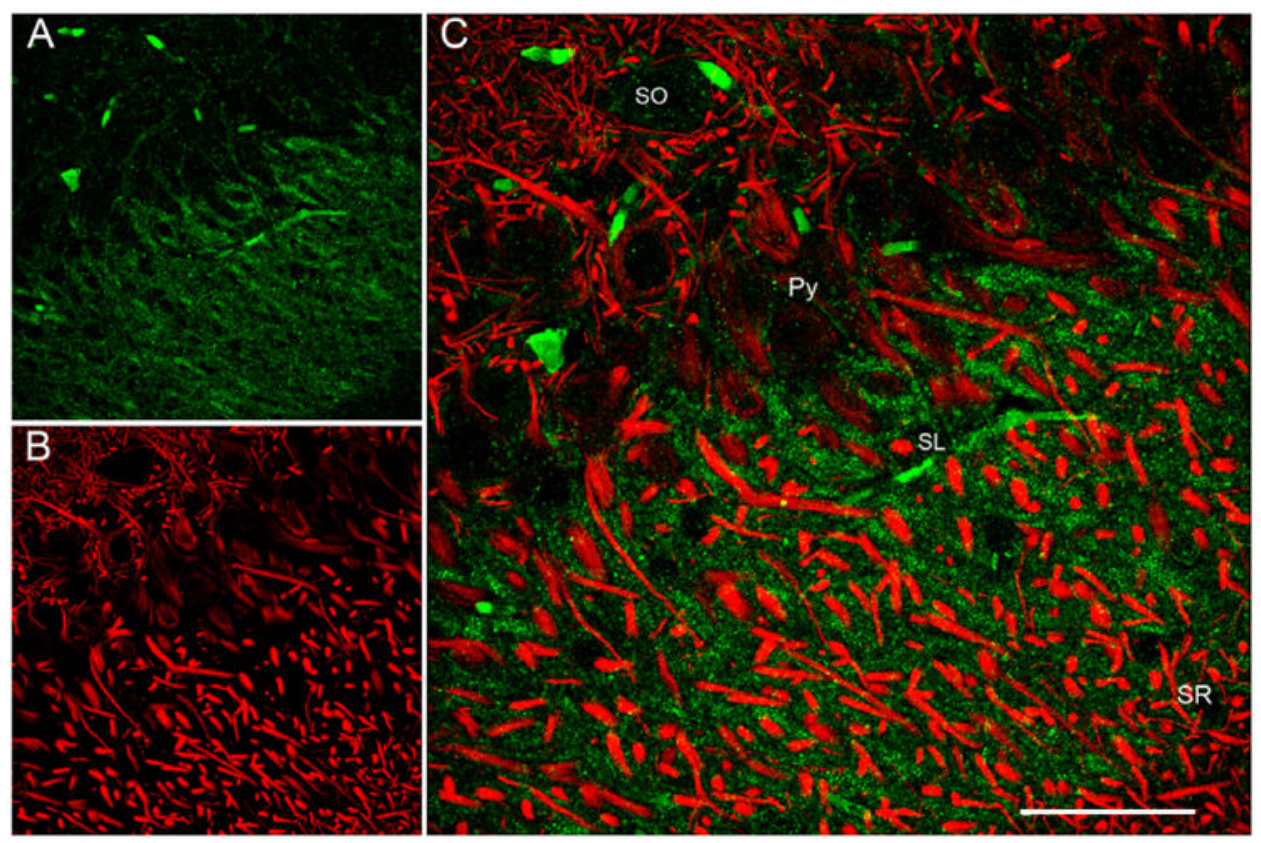

Fig. 5.

Double immunofluorescent labeling for PDE2A (green) and MAP2 (red) in CA3 field of hippocampus (section is $3.5 \mathrm{~mm}$ caudal to bregma). (A) PDE2A channel; staining concentrates in stratum lucidum, likely associated with terminals of mossy fibers. (B) MAP2 channel stains dendritic shafts. (C) Merged image; note minimal overlap between PDE2A and MAP2 fluorescence. Scale bar $=50 \mu \mathrm{m}$. (For interpretation of the references to color in this figure legend, the reader is referred to the web version of this article.) 


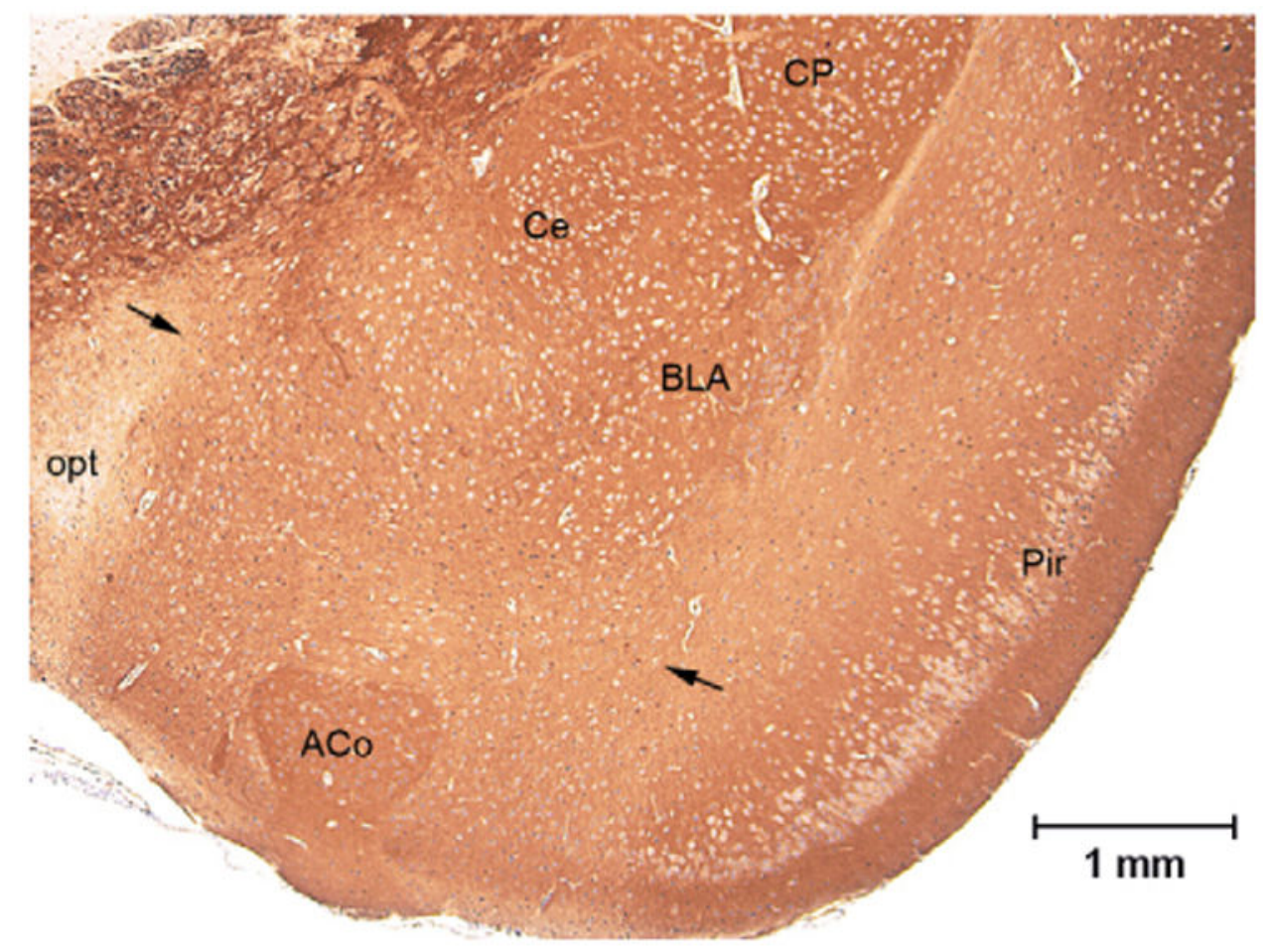

Fig. 6.

PDE2A immunoreactivity in the region of the amygdala (section is $\sim 2.5 \mathrm{~mm}$ caudal to bregma). A band of immunopositive neurons (indicated by arrows) runs between piriform cortex and amygdala, extending medially between anterior cortical and central/basolateral amygdaloid nuclei. 

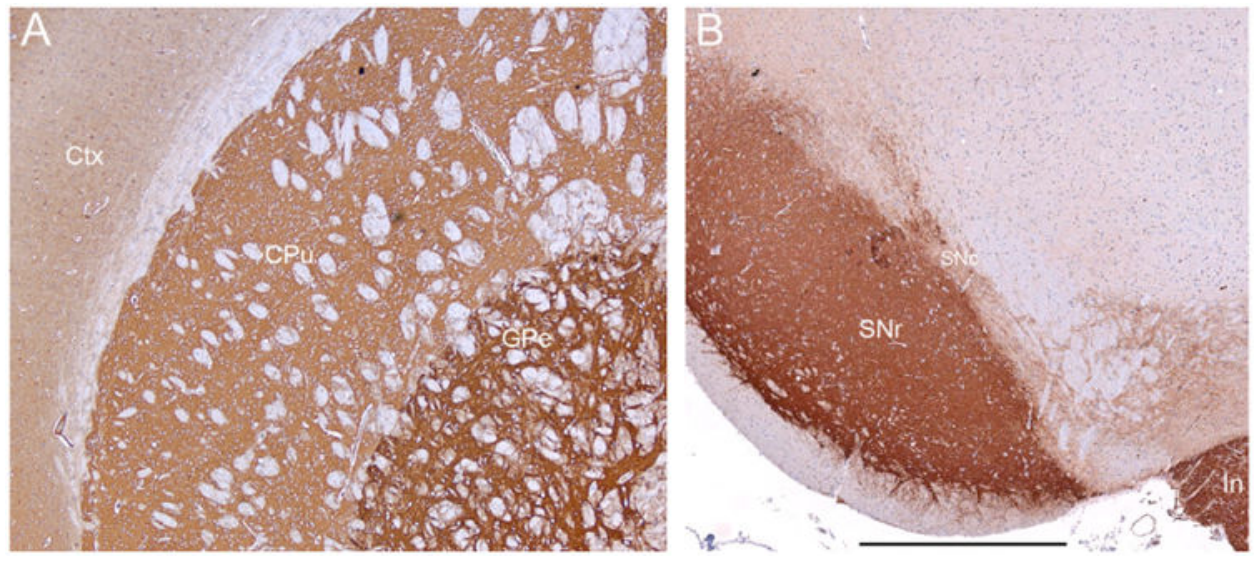

Fig. 7.

PDE2A immunoreactivity in basal ganglia. (A) Staining in caudate-putamen is less dense than in globus pallidus (section $2 \mathrm{~mm}$ caudal to bregma). (B) Dense staining in substantia nigra (pars reticulata) contrasts with weak staining in substantia nigra pars compacta (section is $5.8 \mathrm{~mm}$ caudal to bregma). Very dense staining is also present in the interpeduncular nucleus. Scale bar $=1 \mathrm{~mm}$. 


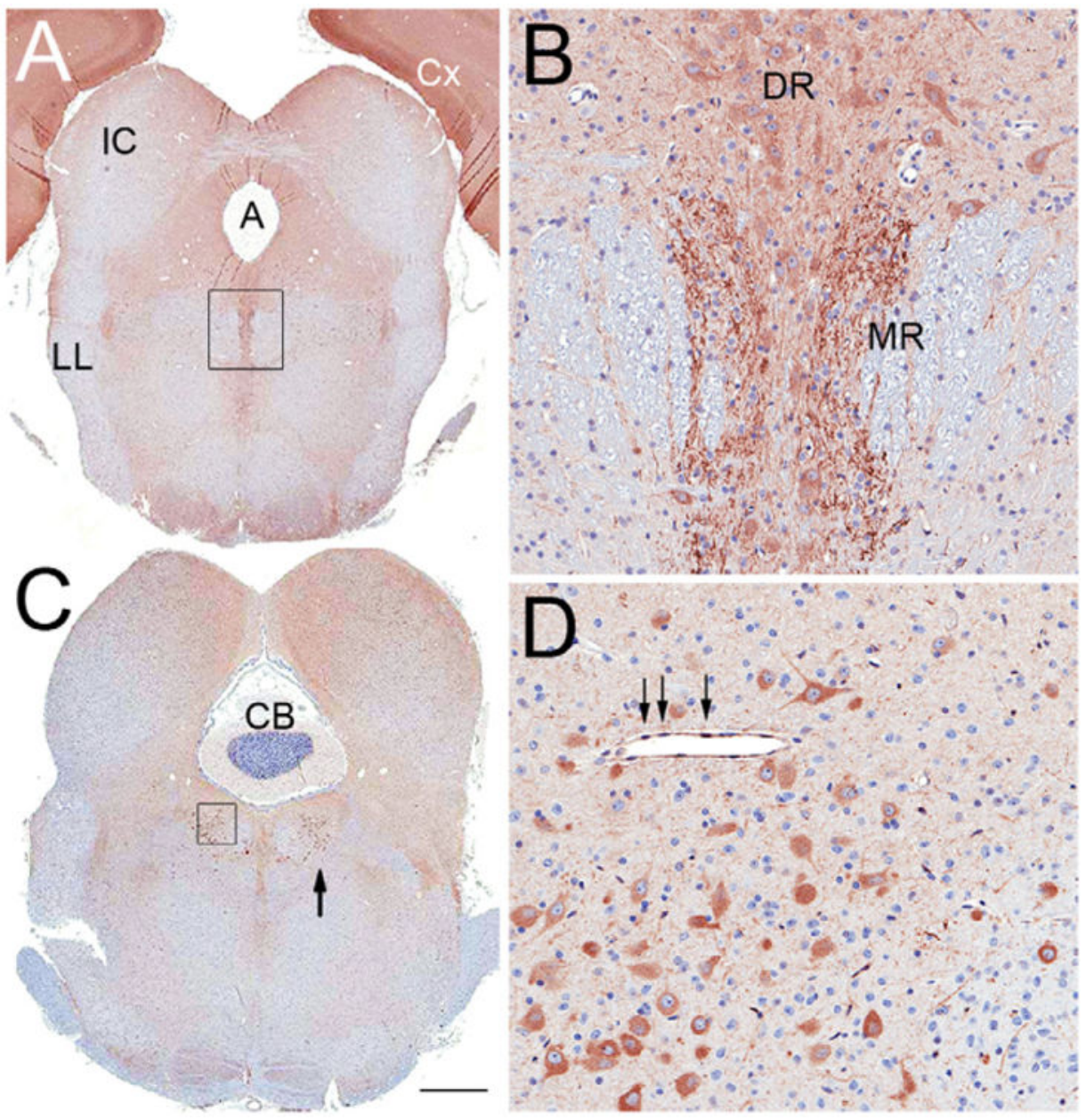

Fig. 8.

PDE2A immunoreactivity in midbrain. (A) Immunostaining is visible in superficial layers of inferior colliculus, the central gray, raphe nuclei, and pyramidal tract, though markedly weaker than in occipital cortex (visible at top); section is $\sim 8.5 \mathrm{~mm}$ caudal to bregma. (B) Higher magnification of boxed zone in A illustrates immunostaining in dorsal and median raphe. (C) A more caudal section (section $\sim 9.2 \mathrm{~mm}$ caudal to bregma); note labeling in the region of lateral dorsal tegmentum (black arrow). (D) Higher magnification of boxed zone in $\mathrm{C}$ shows immunopositive cell bodies. Black arrows point to immunostained endothelial cells lining an arteriole that runs through the section. Scale bar $=1 \mathrm{~mm}(\mathrm{~A}, \mathrm{C}) ; 200 \mu \mathrm{m}(\mathrm{B}) ; 100$ $\mu \mathrm{m}(\mathrm{D})$. 

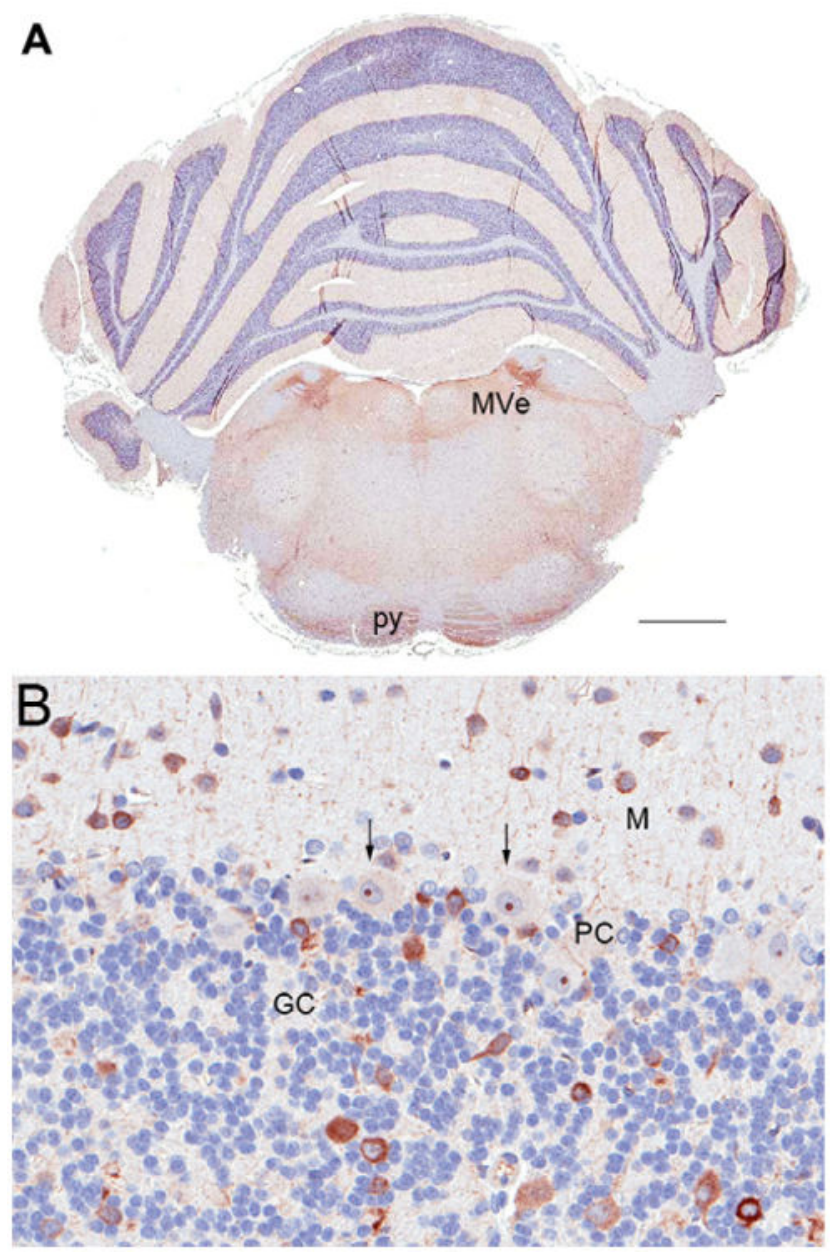

Fig. 9.

PDE2A immunoreactivity in hindbrain and cerebellum. (A) Low magnification view; staining is weak in cerebellar cortex, stronger in vestibular nuclei and pyramidal tract (section is $10.3 \mathrm{~mm}$ caudal to bregma). (B) Higher magnification view shows the molecular/ granule cell border of cerebellar cortex, illustrating weakly stained Purkinje cells (black arrows) and immunoreactive fibers and puncta in the molecular layer. Scattered strongly immunopositive neurons are visible in molecular and granule cell layers (readily identified by the densely packed blue cells). Scale bar $=1 \mathrm{~mm}(\mathrm{~A}) ; 100 \mu \mathrm{m}$ (B). (For interpretation of the references to color in this figure legend, the reader is referred to the web version of this article.) 


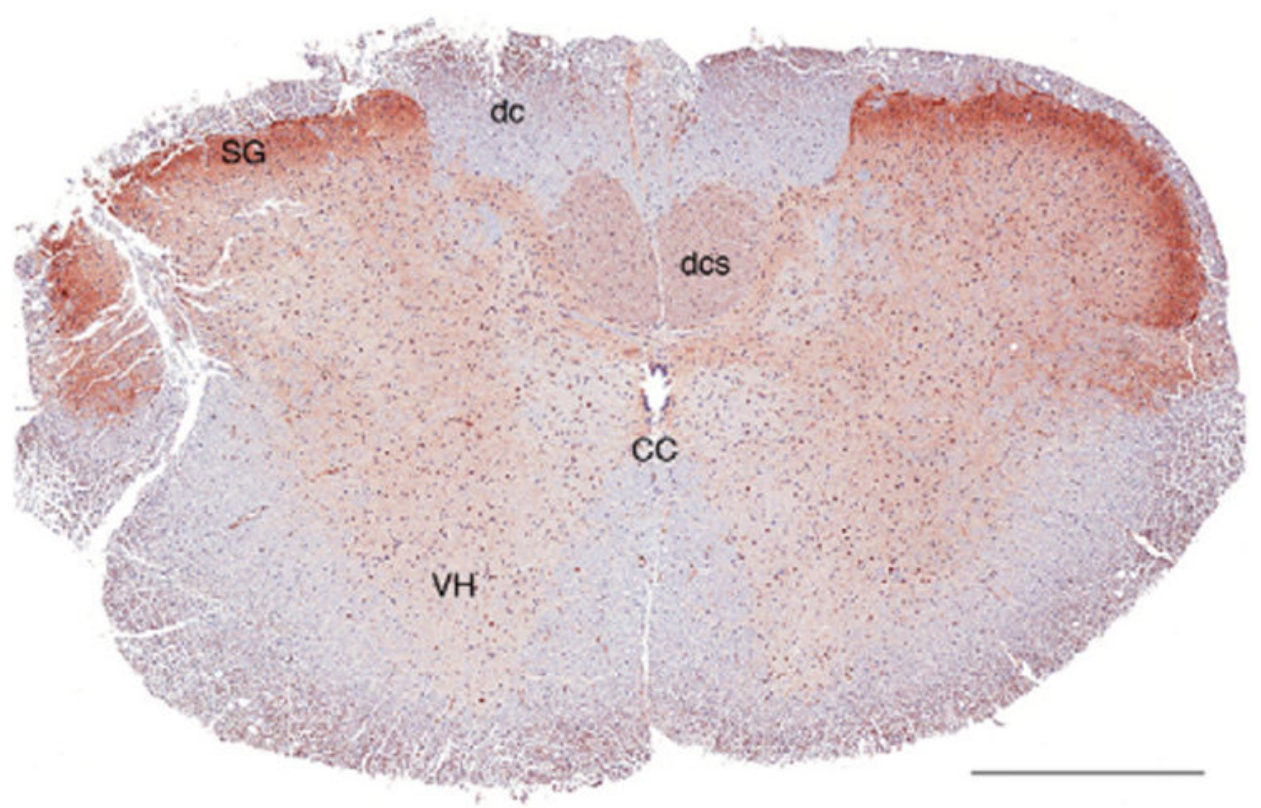

Fig. 10.

PDE2A immunoreactivity in rostral spinal cord (section is from C2). Immunostaining is strongest in the neuropil of the superficial dorsal horn; some immunopositive neurons are scattered about the spinal gray, extending into ventral horn. Note light staining of fibers in corticospinal tract. Scale bar $=500 \mu \mathrm{m}$. 